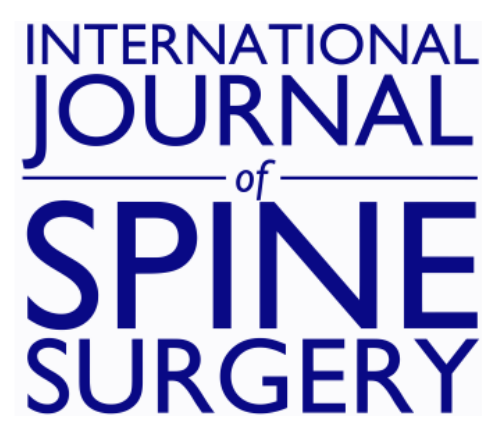

\title{
Short-Term Impact of Bracing in Multi-Level Posterior Lumbar Spinal Fusion
}

Ryan Dimentberg, Saurabh Sinha, Gregory Glauser, Ian F. Caplan, James M. Schuster, Scott D. McClintock, Jang W. Yoon, Paul J. Marcotte, Zarina S. Ali and Neil R. Malhotra

Int J Spine Surg published online 22 September 2021

http://ijssurgery.com/content/early/2021/09/20/8119

This information is current as of April 26, 2023.

Email Alerts Receive free email-alerts when new articles cite this article. Sign up at:

http://ijssurgery.com/alerts

The International Journal of Spine Surgery

2397 Waterbury Circle, Suite 1,

Aurora, IL 60504, Phone: +1-630-375-1432 


\title{
Short-Term Impact of Bracing in Multi-Level Posterior Lumbar Spinal Fusion
}

\author{
RYAN DIMENTBERG, BS, ${ }^{1}$ SAURABH SINHA, MD,${ }^{1}$ GREGORY GLAUSER, MD, MBA, MA, ${ }^{1}$ IAN F. \\ CAPLAN, BS, ${ }^{1}$ JAMES M. SCHUSTER, MD, PHD,${ }^{1}$ SCOTT D. MCCLINTOCK, PHD,${ }^{2}$ JANG W. YOON, MD, \\ MSC, ${ }^{1}$ PAUL J. MARCOTTE, MD,${ }^{1}$ ZARINA S. ALI, MD, MS, ${ }^{1}$ NEIL R. MALHOTRA, MD ${ }^{1,3}$ \\ ${ }^{1}$ University of Pennsylvania Perelman School of Medicine, Department of Neurological Surgery, Philadelphia, Pennsylvania, ${ }^{2}$ West Chester University, \\ Department of Mathematics and West Chester Statistical Institute, West Chester, Pennsylvania, ${ }^{3}$ Translational Spine Research Lab of the University of \\ Pennsylvania, Philadelphia, Pennsylvania
}

\begin{abstract}
Background: Clinical practice in postoperative bracing after posterior lumbar spine fusion (PLF) is inconsistent between providers. This paper attempts to assess the effect of bracing on short-term outcomes related to safety, quality of care, and direct costs.

Methods: Retrospective cohort analysis of consecutive patients undergoing multilevel PLF with or without bracing (2013-2017) was undertaken $(\mathrm{n}=980)$. Patient demographics and comorbidities were analyzed. Outcomes assessed included length of stay (LOS), discharge disposition, quality-adjusted life years (QALY), surgical-site infection (SSI), total cost, readmission within 30 days, and emergency department (ED) evaluation within 30 days.

Results: Amongst the study population, 936 were braced and 44 were not braced. There was no difference between the braced and unbraced cohorts regarding $\operatorname{LOS}(P=.106)$, discharge disposition $(P=.898)$, 30-day readmission $(P=$ .434), and 30-day ED evaluation $(P=1.000)$. There was also no difference in total cost $(P=.230)$ or QALY gain $(P=$ .740). The results indicate a significantly lower likelihood of SSI in the braced population $(1.50 \%$ versus $6.82 \%$, odds ratio $=0.208,95 \%$ confidence interval $=0.057-0.751, P=.037)$. There was no difference in relevant comorbidities $(P=$ $.259-1.000)$, although the braced cohort was older than the unbraced cohort (63 versus 56 y, $P=.003$ ).

Conclusion: Bracing following multilevel posterior lumbar fixation does not alter short-term postoperative course or reduce the risk for early adverse events. Cost analysis show no difference in direct costs between the 2 treatment approaches. Short-term data suggest that removal of bracing from the postoperative regimen for PLF will not result in increased adverse outcomes.
\end{abstract}

Lumbar Spine

Keywords: cost-effectiveness, lumbar fusion, multi-level bracing, outcomes, posterior lumbar spine fusion (PLF), quality improvement

\section{INTRODUCTION}

Posterior lumbar spine fusion (PLF) is indicated for the treatment of a broad range of pathologies, including degenerative disk disease, spondylolisthesis, spinal deformity, and trauma. ${ }^{1}$ Postoperative bracing is a common adjunct following PLF, intended to increase mechanical support and arthrodesis following fusion. However, current estimates show only half of providers employ postoperative bracing for PLF, indicating a lack of consensus regarding its clinical utility. ${ }^{2,3}$

Current studies of the effects of bracing on outcomes in multilevel PLF reveal mixed results. ${ }^{4-}$ 7 Advocates of postoperative bracing suggest that increased spinal immobilization can provide additional support against axial loading and limit gross truncal motion to improve fusion rates. ${ }^{8}$ This is consistent with studies demonstrating a decrease in overall applied force to the spine, ${ }^{9}$ in addition to reduced rates of pseudarthrosis ${ }^{10}$ with bracing. Additionally, proponents of bracing argue that bracing functions as a psychological reminder for patients to limit movement during the short-term postoperative window. ${ }^{2,11}$ However, many practitioners note the difficulty of objectively measuring this effect in patients. ${ }^{3}$

Arguments against bracing point to recent studies that demonstrate no significant difference in level of pain and quality of life in the short-term, ${ }^{12}$ or longterm outcomes ${ }^{5}$ between braced and unbraced cohorts. Furthermore, many suggest that the rigidity and load-bearing capacity of internal 
fixation obviates the need for bracing in the lumbar spine. ${ }^{11,13-15}$ Although uncommon, lumbar braces are associated with adverse events such as pressure ulcers, nerve palsies, skin maceration and muscle atrophy, which calls for more evidence about its purported benefits. ${ }^{11,16}$

The authors of this study have previously shown that bracing after single-level PLF results in no difference in outcomes. However, many studies showing increased facet contact pressure and movement at adjacent disks in multilevel PLF emphasize the need for robust fixation in these more complex cases. ${ }^{17-19}$ Additionally, several studies indicate that bracing is more common for multilevel than single-level fusions. ${ }^{2,11}$ Within the authors' department, there are surgeons who opt to brace after all multilevel PLFs and surgeons who never brace. In the context of mixed evidence in the literature, the decision to brace ultimately is one of surgeon preference/training. Hence, the institution studied herein offers an opportunity for internally controlled comparison between braced and unbraced multilevel PLF patients. As such, this study seeks to expand on the authors prior findings by evaluating short-term outcomes and associated direct costs related to lumbar bracing following multilevel PLF.

\section{MATERIALS AND METHODS}

\section{Study Approval}

This study was approved by the institutional review board (IRB) at the Hospital of the University of Pennsylvania. The IRB number for this study is 825280. A waiver of informed consent was also granted by the IRB because this study was considered to be a minimal risk to patients. All ethical guidelines and rules were followed to protect patient privacy.

\section{Study Population}

Patients undergoing multilevel ( $\geq 2$ levels) PLF for degenerative spine disease at 1 multihospital health system were enrolled retrospectively from July 1, 2013, to June 30, 2017. A retrospective cohort analysis was conducted on consecutive patients $(\mathrm{n}=980)$ using the EpiLog tool. The EpiLog tool is a nonproprietary clinical research and quality improvement architecture that was built and overlaid onto the electronic health record system, which enables prospective data collection. ${ }^{20}$
EpiLog, as an electronic health record enhancement, was used solely as a method for collecting and extracting patient demographic and outcome data.

The study population included all patients undergoing elective multilevel PLF, performed by 20 neurosurgeons at the institution studied herein. The population was separated into braced and unbraced cohorts based on the attending surgeon's practice - of the 20 neurosurgeons, 18 always braced and 2 never braced. No surgeons were found to use bracing on a case-by-case basis. All acute trauma, pediatric, and tumor patients were excluded, and the remaining cases were confirmed as elective by assessing records of office visits in the 30 days prior to surgery for evaluation and imaging. Intraoperative technique and instrumentation used was at the surgeon's discretion, though instrumentation is consistent across the health system due to longterm purchasing agreements.

\section{Data Collection}

Patient data were collected via the EpiLog tool from the electronic health record. Patient characteristics including age, gender, race, American Society of Anesthesiologists (ASA) score, smoking status, pack years, graft type, duration of follow-up, body mass index (BMI), and multiple medical comorbidities were recorded (Table 1). Outcomes assessed were surgical-site infection (SSI), length of stay (LOS), discharge disposition, emergency department (ED) evaluation within 30 days, unplanned readmission within 30 days, and total cost. Total cost was defined as all actual costs directly incurred by the hospital during inpatient stay, retrieved from billing databases. A subset of patients completed the EQ-5D-3L validated questionnaire to calculate quality-adjusted life years (QALY), which was incorporated as a small consecutive prospective pilot.

\section{Statistical Methods}

All continuous variables were assessed with the Student $t$ test or Wilcoxon rank sum test where appropriate. All categorical variables were analyzed with Pearson $\chi^{2}$ test or Fisher exact test. Multivariate logistic regression analyses were used to determine disposition location based on the independent variable of bracing. Significant results were defined as $P<.05$. Averages are presented as mean \pm standard deviation. 
Table 1. Patient demographics and comorbidities. ${ }^{a}$

\begin{tabular}{|c|c|c|c|}
\hline Variable & Brace, n (\%) & No Brace, n (\%) & $P$ Value \\
\hline Sex & & & .8731 \\
\hline Male & $414(44.23)$ & $20(45.45)$ & \\
\hline Female & $522(55.77)$ & $24(54.55)$ & \\
\hline Diabetes & $63(8.01)$ & $3(1.34)$ & .7236 \\
\hline COPD & $5(0.64)$ & $0(0.0)$ & 1.0000 \\
\hline CAD & $4(0.51)$ & $0(0.0)$ & 1.0000 \\
\hline Obesity & $12(1.52)$ & $1(3.45)$ & .3775 \\
\hline $\mathrm{CHF}$ & $6(0.76)$ & $0(0.0)$ & 1.0000 \\
\hline HTN & $168(21.35)$ & $7(24.14)$ & .7191 \\
\hline Smoker & $121(13.02)$ & $6(15.0)$ & .7170 \\
\hline Race & & & .2618 \\
\hline White & $740(79.06)$ & $31(70.45)$ & \\
\hline Nonwhite & $196(20.94)$ & $13(29.55)$ & \\
\hline ASA grade & & & .3549 \\
\hline 1 & $14(1.50)$ & $1(2.27)$ & \\
\hline 2 & $521(55.78)$ & $21(47.73)$ & \\
\hline 3 & 394 (42.18) & $21(47.73)$ & \\
\hline 4 & $5(0.54)$ & $1(2.27)$ & \\
\hline Graft type & & & .9916 \\
\hline Allograft & $50(5.34)$ & $2(4.55)$ & \\
\hline Autograft & $6(0.64)$ & $0(0.0)$ & \\
\hline Structural & $311(33.23)$ & $16(36.36)$ & \\
\hline $\begin{array}{l}\text { Autograft } \\
\quad+\text { structural }\end{array}$ & $3(0.32)$ & $0(0.0)$ & \\
\hline $\begin{array}{l}\text { Allograft } \\
\quad+\text { structural }\end{array}$ & $30(3.21)$ & $1(2.27)$ & \\
\hline \multirow[t]{2}{*}{ None } & $536(57.26)$ & $25(56.82)$ & \\
\hline & Mean (SD) & Mean (SD) & \\
\hline Pack years & $24.06(16.83)$ & $21.11(12.23)$ & .6039 \\
\hline $\begin{array}{l}\text { Total number of } \\
\text { comorbidities }\end{array}$ & $6.16(6.47)$ & 7.50 (7.22) & .5490 \\
\hline BMI & $29.50(5.57)$ & $31.03(8.68)$ & .2589 \\
\hline $\begin{array}{l}\text { Duration of } \\
\text { follow-up }\end{array}$ & $269.5(272.9)$ & $279.6(358.6)$ & .8051 \\
\hline Age & 63.18 (11.92) & $55.80(15.14)$ & .0026 \\
\hline
\end{tabular}

Abbreviations: ASA, American Society of Anesthesiology; BMI, body mass index; $\mathrm{CAD}$, coronary artery disease; $\mathrm{CHF}$, congestive heart failure; $\mathrm{COPD}$, chronic obstructive pulmonary disorder; HTN, hypertension.

${ }^{a}$ Bolded $P$ values are statistically significant $(P<.05)$.

\section{RESULTS}

\section{Patient Demographics}

Of the 980 patients included in our analysis, 936 were braced and 44 were not braced (Table 1). Braced patients were older than unbraced patients $(63.18 \pm 11.92$ versus $55.80 \pm 15.14, P=.003)$. There were no significant gender differences between the braced and unbraced cohorts $(P=.873)$. Additionally, there were no significant differences

Table 2. Multivariate regression of perioperative variables and complications. ${ }^{a}$

\begin{tabular}{lccr}
\hline & Brace, n (\%) & No Brace, n (\%) & P Value \\
\hline SSI & $14(1.50)$ & $3(6.82)$ & $\mathbf{. 0 3 7 0}$ \\
30-d ED visit & $25(2.67)$ & $1(2.27)$ & 1.0000 \\
30-d readmission & $112(11.97)$ & $7(15.91)$ & .4338 \\
Home discharge & $497(53.56)$ & $24(54.55)$ & .8977 \\
$\quad$ & & & \\
\hline
\end{tabular}

Abbreviations: ED, emergency department; SSI, surgical-site infection.

${ }^{a}$ Bolded $P$ values are statistically significant $(P<.05)$.

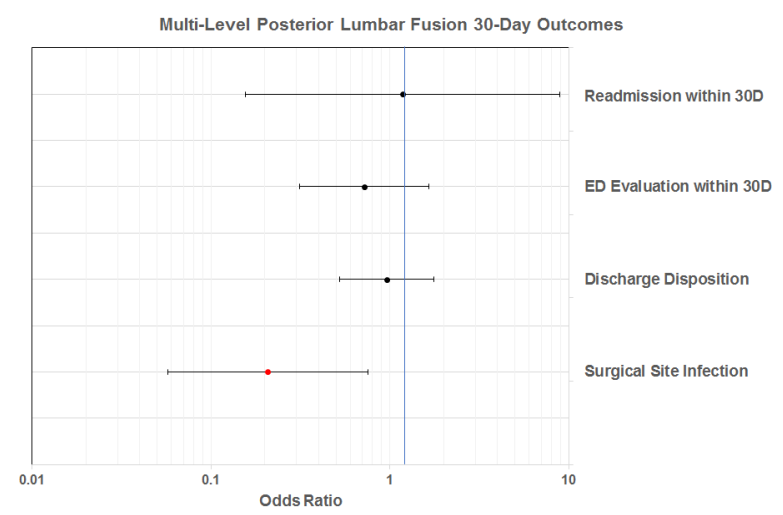

Figure 1. Short-term postoperative risk assessment. Depiction of odds ratios for short-term outcomes following multilevel posterior lumbar spine fusion (PLF). The braced cohort was compared with the nonbrace cohort in reference to 30-day readmission, emergency department (ED) evaluation, and discharge to home or to skilled nursing facility (SNF)/acute rehabilitation facility (ARF).

with respect to race $(P=.262)$, ASA grade $(P=$ $.355)$, graft type $(P=.992)$, smoking status $(P=$ $.717)$, BMI $(P=.259)$, pack years $(P=.604)$, total number of comorbidities $(P=.550)$, and all individual comorbidities $(P=.377-1.000)$.

\section{Postoperative Outcomes}

Postoperatively, there was no significant difference in unplanned 30-day readmission $(P=.434)$, ED evaluation within 30 days $(P=1.000)$, discharge disposition $(P=.898)$, and $\operatorname{LOS}(P=.106)$ between the braced and unbraced cohorts. However, braced patients demonstrated a decreased rate of surgicalsite infection $(1.50 \%$ versus $6.82 \%$, odds ratio $=$ $0.208,95 \%$ confidence interval $=0.057-0.751, P=$ 0.037) (Table 2; Figure 1).

\section{Quality and Cost Effectiveness}

QALY gain was similar between braced and unbraced patients $(P=.740)$ (Table 3). Costs incurred were slightly greater for braced patients; however, this result did not reach a level of significance $(11114.7 \pm 7797.7$ versus $9328.1 \pm$ 5788.7, $P=.230)$.

Table 3. Comparison of quality and cost of care. ${ }^{a}$

\begin{tabular}{lccc}
\hline & $\begin{array}{c}\text { Brace, } \\
\text { Mean (SD) }\end{array}$ & $\begin{array}{c}\text { No Brace, } \\
\text { Mean (SD) }\end{array}$ & $\boldsymbol{P}$ Value \\
\hline LOS (h) & $126.1(125.9)$ & $183.9(193.3)$ & .1064 \\
Total cost (USD) & $11,114.7(7797.7)$ & $9,328.1(5788.7)$ & .2303 \\
QALY gain & $0.09(0.18)$ & $0.02(\mathrm{~N} / \mathrm{A})$ & .7398 \\
\hline
\end{tabular}

Abbreviations: LOS, length of stay; QALY, quality-adjusted life years; USD,

United States dollars.

${ }^{a}$ Bolded $P$ values are statistically significant $(P<.05)$. 


\section{DISCUSSION}

Due to a paucity of research, it has been challenging for physicians to make an informed decision about bracing. This study demonstrates that there is minimal difference in outcomes between braced and unbraced patients following multilevel PLF. Compared with unbraced patients, braced patients had similar rates of readmission and ED evaluation within 30 days, in addition to comparable LOS. Further, there were no differences in hospital cost or patient described quality of life between the 2 cohorts. However, braced patients were 5 times less likely to obtain a SSI during the course of their treatment.

These findings are in line with recent studies aimed at assessing the efficacy of postoperative bracing. In previous investigations, the authors of the present study showed that there is no significant benefit of postoperative bracing for single-level PLF and single-level anterior cervical spine discectomy and fusion (ACDF). ${ }^{21,22}$ Similarly, the authors previously found mixed benefits for bracing in multilevel ACDF populations. ${ }^{23}$ Further, a recent meta-analysis found that there was no support for bracing following a host of spine surgeries including PLF, ACDF, thoracic posterior decompression and fusion, and cervical laminoplasty, as measured by patient-reported efficacy, radiographic outcomes, safety, and cost-effectiveness. ${ }^{24}$ Nonetheless, the literature still lacks evidence to clearly delineate the clinical utility of multilevel PLF from a broader patient population.

The current study suggests that bracing may not be indicated as standard of care, given the lack of significant short-term differences in outcomes between the 2 groups. However, there may be cases where it provides benefit for a subset of the patient population and over the long-term, such as arthrodesis. It is well described that risk factors such as smoking and diabetes have detrimental effects on bone health and healing, contributing to lower fusion rates and worse outcomes. ${ }^{25-28}$ As such, bracing may be better considered from an individualized perspective in relation to a patient's specific comorbidities and corresponding likelihood of complications.

The cost of lumbar braces, which was not calculated into cost estimates, can range from $\$ 1200$ to over $\$ 2400 .^{29}$ The opportunity to eliminate this significant cost, while maintaining outcomes, may indicate that foregoing bracing can provide the highest value care to patients. ${ }^{30}$ To verify this, prospective controlled studies with a balanced population size are necessary to determine whether foregoing a brace is a safe and effective option.

Notably, the bracing cohort demonstrated a lower likelihood of SSI. To the authors best knowledge, no other study has identified bracing as a risk-mitigating factor for SSI following PLF. ${ }^{31-35}$ Several studies have indicated bracing in conjunction with antibiotic treatment for SSI; however, this has been directed mainly at patient comfort. $^{36,37}$ Further, a recent meta-analysis indicated that the reported rates of SSI following lumbar fusion range from $0.7 \%$ to $12 \%$, demonstrating the wide variability in outcomes amongst patient populations. ${ }^{35}$ Given that age has been identified as an independent risk-factor for SSI, ${ }^{38,39}$ the significant difference in age between the braced and unbraced populations may serve as an alternate explanation of this finding. Better understanding this relationship is critical, given that SSI is a major cause of preventable health care expenditurescosting between $\$ 15,800$ and $\$ 43,900$ for spinal surgery cases. ${ }^{35,40}$ Given that the effect size was minimal, further research is required to confirm this result in a larger, balanced patient population.

This study aimed to assess the short-term efficacy of bracing in a heterogeneous, multilevel PLF population. Surgeon-specific practices of strictly bracing or not bracing patients avoided the bias of patient selection, which is reflected in the similarity between the braced and unbraced populations. This analysis was not powered to determine if differences in graft-type or individual comorbidities generated differential short-term outcomes in these patients, but again this study intended to include variability in patient presentation and surgical practice, in order to generalize results to all elective multilevel PLF cases.

\section{Limitations}

There are several limitations to this study design. The study is limited by its retrospective cohort design, despite the use of the prospective data gathering EpiLog tool. Recording bias is an essential problem with all retrospective studies and could not be mitigated. In light of this, data are reported as means and standard deviations, without removing outliers to prevent selection bias in our analysis. Further, the limited number of patients with QALY data reduces the impact and general- 
izability of these findings. Future prospective studies with a focus on gathering robust QALY data will serve to confirm the preliminary findings shown here.

The imbalance in sample size between the braced and unbraced cohorts served as another limiting factor. This imbalance between groups was a result of surgeon practice within the department, as more surgeons opt to brace patients following PLF operations. As a result, there is a smaller cohort of unbraced patients, which reduces statistical power of the study and enhances the opportunity for confounding effects. However, comparison of demographic data found that the 2 groups were not significantly different, aside from the braced cohort being older $(P=.003)$, which suggests that confounding differences between groups should be minimal. The univariate analyses reported are representative of the relationship between bracing and patient outcomes, but did not incorporate preoperative variables in the analysis. The authors intend to expand the patient population to generate a propensity score-matched trial design, to further control for differing demographic and treatmentlevel characteristics. Further equivocal results would suggest the value of a prospective randomized control trial.

\section{CONCLUSION}

The results of this study provide initial evidence as to the equivalence in short-term outcomes with or without bracing in multilevel PLF. Further studies assessing the connection between bracing and SSI, in addition to analyzing long-term outcomes such as reoperation rates and pseudarthrosis, will serve to guide surgical practice and identify areas to improve value of care.

\section{ACKNOWLEDGMENTS}

The authors acknowledge The EpiLog Project.

\section{REFERENCES}

1. DiPaola CP, Molinari RW. Posterior lumbar interbody fusion. J Am Acad Orthopaedic Surg. 2008;16(3):130-139.

2. Bible JE, Biswas D, Whang PG, Simpson AK, Rechtine GR, Grauer JN. Postoperative bracing after spine surgery for degenerative conditions: a questionnaire study. Spine $J$. 2009;9(4):309-316.

3. Elsenbeck MJ, Wagner SC, Milby AH. Is routine bracing of benefit following posterior instrumented lumbar fusion for degenerative indications? Clin Spine Surg. 2018;31(9):363-365.

4. Kim SS, Denis F, Lonstein JE, Winter RB. Factors affecting fusion rate in adult spondylolisthesis. Spine. 1990;15(9):979-984.

5. Yee A, Yoo J, Marsolais E, et al. Use of a postoperative lumbar corset after lumbar spinal arthrodesis for degenerative conditions of the spine: a prospective randomized trial. JBJS. 2008;90(10):2062-2068.

6. Christensen FB, Hansen ES, Laursen M, Thomsen K, Bünger CE. Long-term functional outcome of pedicle screw instrumentation as a support for posterolateral spinal fusion: randomized clinical study with a 5-year follow-up. Spine. 2002;27(12):1269-1277.

7. Fritzell P, Hägg O, Wessberg P, Nordwall A; Swedish Lumbar Spine Study Group. Chronic low back pain and fusion: a comparison of three surgical techniques: a prospective multicenter randomized study from the Swedish Lumbar Spine Study Group. Spine. 2002;27(11):1131-1141.

8. Johnsson R, Strömqvist B, Axelsson P, Selvik G. Influence of spinal immobilization on consolidation of posterolateral lumbosacral fusion. A roentgen stereophotogrammetric and radiographic analysis. Spine. 1992;17(1):16-21.

9. Nachemson A, Morris JM. In vivo measurements of intradiscal pressure: discometry, a method for the determination of pressure in the lower lumbar discs. JBJS. 1964;46(5):1077-1092.

10. Skoch J, Zoccali C, Zaninovich O, et al. Bracing after surgical stabilization of thoracolumbar fractures: a systematic review of evidence, indications, and practices. World Neurosurg. 2016;93:221-228.

11. Connolly PJ, Grob D. Controversy: bracing of patients after fusion for degenerative problems of the lumbar spine-yes or no? Spine. 1998;23(12):1426-1428.

12. Soliman HA, Barchi S, Parent S, Maurais G, Jodoin A, Mac-Thiong J-M. Early impact of postoperative bracing on pain and quality of life after posterior instrumented fusion for lumbar degenerative conditions. Spine. 2018;43(3):155-160.

13. Stonecipher T, Wright S. Posterior lumbar interbody fusion with facet-screw fixation. Spine. 1989;14(4):468-471.

14. Humphreys SC, Hodges SD, Patwardhan AG, Eck JC, Murphy RB, Covington LA. Comparison of posterior and transforaminal approaches to lumbar interbody fusion. Spine. 2001;26(5):567-571.

15. Axelsson P, Johnsson R, Strömqvist B. Effect of lumbar orthosis on intervertebral mobility. A roentgen stereophotogrammetric analysis. Spine. 1992;17(6):678-681.

16. Schroeder S, Rössler H, Ziehe P, Higuchi F. Bracing and supporting of the lumbar spine. Prosthetics Orthotics Int. 1982;6(3):139-146.

17. Panjabi M, Malcolmson G, Teng E, Tominaga $\mathrm{Y}$, Henderson G, Serhan H. Hybrid testing of lumbar CHARITE discs versus fusions. Spine. 2007;32(9):959-966.

18. Nunley PD, Jawahar A, Mukherjee DP, et al. Comparison of pressure effects on adjacent disk levels after 2level lumbar constructs: fusion, hybrid, and total disk replacement. Surgical Neurol. 2008;70(3):247-251.

19. Lackey A, Phan K, Mobbs R. A systematic review and meta-analysis of outcomes in hybrid constructs for multi-level lumbar degenerative disc disease. J Clin Neurosci. 2016;34:2329 
20. Gawande A. Why doctors hate their computers. The New Yorker. 2018;12.

21. Caplan I, Sinha S, Schuster J, et al. The utility of cervical spine bracing as a postoperative adjunct to single-level anterior cervical spine surgery. Asian J Neurosurg. 2019;14(2):461.

22. Sinha S, Caplan I, Schuster J, et al. Evaluation of lumbar spine bracing as a postoperative adjunct to single-level posterior lumbar spine surgery. Asian J Neurosurg. 2020;15(2):333-337.

23. Caplan I, Sinha S, Schuster J, et al. The utility of cervical spine bracing as a postoperative adjunct to multilevel anterior cervical spine surgery. Int J Spine Surg. 2020;14(2):151-157.

24. Zhu MP, Tetreault LA, Sorefan-Mangou F, Garwood P, Wilson JR. Efficacy, safety, and economics of bracing after spine surgery: a systematic review of the literature. Spine J. 2018;18(9):1513-1525.

25. Yan C, Avadhani NG, Iqbal J. The effects of smoke carcinogens on bone. Curr Osteoporos Rep. 2011;9(4):202.

26. Lee JJ, Patel R, Biermann JS, Dougherty PJ. The musculoskeletal effects of cigarette smoking. JBJS. 2013;95(9):850-859.

27. Lidar Z, Beaumont A, Lifshutz J, Maiman DJ. Clinical and radiological relationship between posterior lumbar interbody fusion and posterolateral lumbar fusion. Surgical Neurol. 2005;64(4):303-308.

28. Browne JA, Cook C, Pietrobon R, Bethel MA, Richardson WJ. Diabetes and early postoperative outcomes following lumbar fusion. Spine. 2007;32(20):2214-2219.

29. Agabegi SS, Asghar FA, Herkowitz HN. Spinal orthoses. J Am Acad Orthopaedic Surg. 2010;18(11):657-667.

30. Porter ME. What is value in health care? $N$ Engl $J$ Med. 2010;363(26):2477-2481.

31. Fang A, Hu SS, Endres N, Bradford DS. Risk factors for infection after spinal surgery. Spine. 2005;30(12):1460-1465.

32. Olsen MA, Mayfield J, Lauryssen C, et al. Risk factors for surgical site infection in spinal surgery. $J$ Neurosurg Spine. 2003;98(2):149-155.

33. Ter Gunne AFP, Cohen DB. Incidence, prevalence, and analysis of risk factors for surgical site infection following adult spinal surgery. Spine. 2009;34(13):1422-1428.

34. Chaichana KL, Bydon M, Santiago-Dieppa DR, et al. Risk of infection following posterior instrumented lumbar fusion for degenerative spine disease in 817 consecutive cases. $J$ Neurosurg Spine. 2014;20(1):45-52.

35. Klemencsics I, Lazary A, Szoverfi Z, Bozsodi A, Eltes P, Varga PP. Risk factors for surgical site infection in elective routine degenerative lumbar surgeries. Spine $J$. 2016;16(11):1377-1383.
36. Meredith DS, Kepler CK, Huang RC, Brause BD, Boachie-Adjei O. Postoperative infections of the lumbar spine: presentation and management. Int Orthopaedics. 2012;36(2):439-444.

37. Butler JS, Wagner SC, Morrissey PB, et al. Strategies for the prevention and treatment of surgical site infection in the lumbar spine. Clin Spine Surg. 2018;31(8):323-330.

38. Koutsoumbelis S, Hughes AP, Girardi FP, et al. Risk factors for postoperative infection following posterior lumbar instrumented arthrodesis. JBJS. 2011;93(17):1627-1633.

39. Kaye KS, Schmit K, Pieper C, et al. The effect of increasing age on the risk of surgical site infection. J Infect Dis. 2005;191(7):1056-1062.

40. Featherall J, Miller JA, Bennett EE, et al. Implementation of an infection prevention bundle to reduce surgical site infections and cost following spine surgery. JAMA Surg. 2016;151(10):988-990.

Disclosures and COI: This research received no specific grant from any funding agency in the public or commercial sectors. Support was received from the Kevin and Bernadette McKenna Family Research Fund. The authors have no personal or institutional interest with regards to the authorship and/or publication of this manuscript.

Corresponding Author: Neil R. Malhotra, MD, Chief of Neurosurgery - HUP, Vice Chairman for Operations, Associate Professor and Associate Program Director, Hospital of the University of Pennsylvania, Department of Neurosurgery, 3rd Floor Silverstein Pavilion, 3400 Spruce St, Philadelphia, PA 19104. Phone: (215)662-3487; Fax: (215) 349-5534; Email: neil.malhotra@pennmedicine. upenn.edu.

Published 0 Month 2021

This manuscript is generously published free of charge by ISASS, the International Society for the Advancement of Spine Surgery. Copyright (C) 2021 ISASS. To see more or order reprints or permissions, see http://ijssurgery.com. 